\title{
Nail Infection, CTCAE
}

National Cancer Institute

\section{Source}

National Cancer Institute. Nail Infection, CT CAE. NCI Thesaurus. Code C143695.

A disorder characterized by an infectious process involving the nail. 